\title{
A Comparative Case Control Study between Innovations Team Malta and Innovations Project UK Working with Hard to Reach Young People with Complex Mental Disorders
}

Andrea Saliba ( $\nabla$ andrea.a.saliba@gov.mt) University of Malta Medical School https://orcid.org/0000-0003-3263-9987

Nigel Camilleri

University of Malta Medical School

Research article

Keywords: Adolescence, Assessment, complex mental disorder, Hard to reach young people, Innovative, Intervention, Mental health, Prognosis

Posted Date: August 12th, 2020

DOI: https://doi.org/10.21203/rs.3.rs-53212/v1

License: (a) (i) This work is licensed under a Creative Commons Attribution 4.0 International License.

Read Full License 


\section{Abstract}

Background

Hard-to-reach young people (HTRYP) can be defined as YP at risk, disadvantaged, marginalised, who slip through the healthcare system and are unwilling to engage with services.

Method

This case control study compared the outcomes from two HTRYP services, Innovations Team Malta (IT Malta) and Innovations Project UK (IP UK) and a matched control from a UK based Community Mental Health Team (CMHT) over a 12 month period. IT Malta included HTRYP 13-25 years and IP UK 15-25 years. An in-depth MDT assessment was carried out together with the Health of the Nation Outcome Scales for Child and Adolescent Mental Health (HoNOSCA) and Children's Global Assessment Scale (CGAS) at assessment and discharge. HTRYP meeting criteria were offered intensive individual tailored therapy.

Results

38 YP were referred to IT Malta, 34 (89.5\%) assessed and 22 (57.9\%) treated in 2018. 40 referrals to IP UK, 36 (90\%) assessed, 31 (86\%) met criteria and 15(48\%) were treated. The HoNOSCA for IT Malta and IP UK were similar, at baseline $(20.65,19.32)$ and discharge $(16.65,16.53)$ respectively, but higher when compared to CMHT $(11.19,8.03)(p<0.001)$. The mean baseline CGAS for IT Malta (46.0) elucidates more impairment compared to IP UK (51.1) and CMHT (58.9). The total mean contact time (hours) per YP were; IT Malta (24.5), IP UK (18.2) and CMHT (8.6).

Conclusion

IT Malta and IP UK identified, engaged and treated YP with multiple complex mental disorders whose needs were not being met by other mental health services. HTRYP may benefit from a flexible YP oriented service, including outreach capability and a focus on engagement. Despite improvement, HTRYP's mental and social functioning remained clinically worse than $\mathrm{CMHT}$.

\section{A Key Practitioner Message}

1. There are a number of young people who are suffering from complex mental disorders and despite this, are refusing to access services or are slipping through the healthcare system.

2. Both Innovations Project UK and Innovations Team Malta were able to identify a similar cohort of hard to reach young people suffering from complex mental disorders when compared to community mental health team.

3. Following access to individualised tailored therapy, a significant improvement in mental state and social function was observed in both hard to reach services. 
4. Investment in time and therapeutic engagement has shown to improve attendance rate and yield better treatment outcomes.

5. Hard to reach young people would benefit from a specific dedicated service with an outreach component which has a high staff to patient ratio.

6. We propose a possible ceiling effect that is reached with the improvement in hard to reach young people's mental state and social functioning as these remained clinically worse than young people attending $\mathrm{CMHT}$.

\section{Background}

As part of normal development, adolescents negotiate multiple transitions in many aspects of their life, these include; furthering education or employment and becoming independent so as to individualise into unique adults. Often the adolescent period has been described as being one of high-risk. Many YP tend to be "unprepared for transitions" or ill-equipped for the multiple challenges of adolescence and consequently, their mental disorders may worsen $(p<0.05)$ (Camilleri et al., 2017). These transitions compounded with other psychosocial stressors make young people (YP) more vulnerable to particular risks such as mental disorders (Camilleri et al., 2017).

5-10\% of YP are defined as 'hard to reach' (HTRYP). These HTRYP are particularly vulnerable individuals who are at risk of coming from disadvantaged backgrounds, ending up being marginalised, sometimes homeless and who often slip through the health care system or are unwilling to engage in services (Camilleri et al., 2017). For the purpose of this study the term HTRYP will be used to describe such a person.

In order to access specialised services, a referral by a GP is required, which to a YP with complex needs may be a barrier to access services. Furthermore, most mental health services are associated with high levels of stigma. Another barrier to accessing mental health services is age. Singh et al. (2010) in a systematic review on transition of YP between children to adult services, report that $30-60 \%$ of YP slip through the 'service gap' and as a result are lost to follow up (Gondek et al., 2017).

The Innovations Project (IP UK) 15 to 25 years was a multidisciplinary team based in the North East of England throughout 2011 and was developed to provide a service which identified, assessed and treated HTRYP (Camilleri et al., 2017). The Innovation Team Malta (IT Malta) is a specialist community-based service established in January 2018 within the National Children and Young People's Service (CYPS), Malta for YP aged 13 to 25 years who could not be managed within existing services. The aim for this team was to offer an intensive and flexible service, which focused on using an in-depth multimodal developmental assessment, followed by individualised community-based outreach care plans.

The aim of this study was to compare the service offered, demographics, mental disorders and social functioning of the IT Malta to a similar UK service (IP UK) and with a matched sample from a community mental health team (CMHT). The latter; was a CMHT also based in the North East England. The 
alternative hypothesis was that there were no significant clinical differences found between IT Malta and IP UK, however a statistically significant change would be found in the mental state and social functioning of IT Malta and IP UK from TP1 (baseline) to TP2 (discharge) when compared to CMHT cohort of YP over a maximum period of twelve months.

\section{Methods}

This case control study compared the outcomes from two service evaluations (IT Malta and IP UK) and a matched group from a UK based CMHT. The organisational setup of the IT Malta service was mapped onto IP UK, meaning the team consisted of a multidisciplinary team (MDT) having different child and adolescent mental health training backgrounds. The same protocol used in IP UK was amended and adapted for use in IT Malta (Camilleri et al., 2017).

In order to decrease barriers to access, both IT Malta and IP UK accepted referrals from; GPs, social services, schools, self-referrals or walk-ins. Both IT Malta and IP UK carried out a multimodal in-depth clinical assessment which consisted of a clinical psychiatric interview carried out by a child and adolescent psychiatrist. This entailed a neurodevelopmental assessment which was substantiated by the use of the Mini-International Neuropsychiatric Interview for Children and Adolescents (MINI Kid) (Sheehan et al., 2010). A social function interview was carried out by mental health nurses or a social worker, this was substantiated by the Assessment Schedule for Adolescents (SNASA) (Kroll et al., 1999).

Psychologists carried out a systemic clinical interview informed by the use of Systemic Clinical Outcome and Routine Evaluation (SCORE-15) (Stratton, Bland, Janes, \& Lask, 2010).

Following the completion of the described assessment every YP would be discussed at an MDT formulation meeting, only those who met the criteria described within the service protocol for HTRYP (Camilleri et al., 2017) and deemed to be suffering from complex mental disorders would be taken on for treatment. Those YP who did not meet criteria would be discharged from IP UK or IT Malta and referred to other appropriate services. HTRYP taken on for intervention would be allocated a key worker who would be responsible for coordinating the intervention plan and ensuring appropriate liaison with external agencies. All interventions would be tailored to meet the needs of the YP (therefore were not manualised). Initially the mainstay of intervention would focus on engagement. This was followed by providing the appropriate time needed (at times more than once weekly) to apply evidence based interventions. This consisted of psychopharmacology, home visits, outreach meetings held in the community, supportive psychotherapy, cognitive behaviour therapy, dialectical behaviour therapy skills (DBT), family therapy, social worker involvement and if required admissions to in-patient units.

The outcome measures used in this study consisted of the Health of the Nation Outcome Scales for Child and Adolescent Mental Health (HoNOSCA) and Children's Global Assessment Scale (CGAS). HoNOSCA scores are reported (Gowers, Harrington, ..., \& 1999, n.d.) to have good inter-rater reliability (0.82 for psychiatric symptoms and $0.42-0.62$ for physical and social impairment), good test re-test reliability 0.69 ( $p<0.001$, two tailed Pearson correlation), interclass correlations greater than 0.8 and good face validity 
(Garralda, Yates, Psychiatry, \& 2000, n.d.). The CGAS is widely available and reported to have good joint reliability is of $0.83-0.92$ good inter-rater reliability and a useful measure of change over time (B. Green, Shirk, Hanze, ..., \& 1994, n.d.).

Data from IT Malta were compared with IP UK and CMHT using SPSS (S. B. Green \& Salkind, 2013). YP from IP UK and CMHT were matched for age, gender, education, socioeconomic status, primary diagnosis and degree of severity of mental disorder (Camilleri et al., 2017). The Chi Squared test was used to investigate the association between two categorical variables whereas the one-way ANOVA test was used to compare mean quantitative measurements between the 3 independent groups; CMHT (UK control), IP UK (UK case), IT Malta (Malta case). The Tukey Post-HOC test was essential to compare the mean measurements between the groups two at a time.

\section{Results}

38 YP referred were accepted by IT Malta for assessment, 34 (89.5\%) were assessed, 11 (28.9\%) were discharged, $5(13.1 \%)$ refused assessment and $22(57.9 \%)$ received intensive treatment by the end of 2018.

Comparatively for IP UK, 40 referrals were received, 36 (90\%) were assessed over the one year period, 31 (86\%) met criteria for HTRYP and $15(48 \%)$ were offered individually tailored therapy. Both services were compared to 115 systematically selected and matched YP who attended CMHT. The mean age at referral was 16.21 years (SD 2.8) for IT Malta, which was lower than IP UK (mean 18.48, SD 2.3) and CMHT (mean 19.34, SD 2.9) $p<0.001$.

Table 1

Comparison of demographics between IT Malta, IP UK and CMHT (UK)

\begin{tabular}{|c|c|c|c|c|c|}
\hline & & $\begin{array}{l}\text { UK } \\
\text { (Control) }\end{array}$ & $\begin{array}{l}\text { UK } \\
\text { (Case) }\end{array}$ & $\begin{array}{l}\text { Malta } \\
\text { (Case) }\end{array}$ & $p$ value \\
\hline \multirow[t]{2}{*}{ Gender } & Female & $70.6 \%$ & $61.3 \%$ & $31.6 \%$ & \multirow{2}{*}{$\begin{array}{l}X^{2}(2)=15.41, p< \\
0.001\end{array}$} \\
\hline & Male & $29.4 \%$ & $38.7 \%$ & $68.4 \%$ & \\
\hline \multirow{3}{*}{$\begin{array}{l}\text { Accommodation at } \\
\text { referral }\end{array}$} & Stable & $96.9 \%$ & $51.6 \%$ & $85.3 \%$ & \multirow{3}{*}{$\begin{array}{l}X^{2}(4)=32.216, p< \\
0.001\end{array}$} \\
\hline & Unstable & $3.1 \%$ & $41.9 \%$ & $14.7 \%$ & \\
\hline & Homeless & $0.0 \%$ & $6.5 \%$ & $0.0 \%$ & \\
\hline \multirow{3}{*}{$\begin{array}{l}\text { In education/ } \\
\text { employment }\end{array}$} & Employed & $3.1 \%$ & $0.0 \%$ & $18.8 \%$ & \multirow{3}{*}{$\begin{array}{l}x^{2}(6)=76.69, p< \\
0.001\end{array}$} \\
\hline & Unemployed & $0.0 \%$ & $71.0 \%$ & $43.8 \%$ & \\
\hline & $\begin{array}{l}\text { Long sick } \\
\text { leave }\end{array}$ & $0.0 \%$ & $3.2 \%$ & $0.0 \%$ & \\
\hline
\end{tabular}


The majority of referrals to CMHT were received from GPs (71.4\%) whereas CYPS (24.4\%), looked after children (26.8\%) and GPs (17.1\%) mainly referred to the IP UK. There were no direct referrals from GPs to IT Malta and YP were mainly referred from CYPS (33.3\%), walk-in (25\%), adult services $(20.8 \%)$ or directly from the in-patient psychiatry hospital upon discharge $(16.7 \%), X^{2}(20)=109.38, p<0.001$. The majority of YP referred to both HTRYP services had previous service involvement when compared to $\mathrm{CMHT}\left(\mathrm{X}^{2}(2)=\right.$ 23.596, $p<0.001)$.

Table 2

Comparison service input between IT Malta, IP UK and CMHT (UK)

\begin{tabular}{|c|c|c|c|c|}
\hline & & Mean & Std. Deviation & P-value \\
\hline \multirow[t]{3}{*}{ Days Awaiting Initial Assessment } & СMHT (Control) & 12.18 & 12.105 & \multirow[t]{3}{*}{0.009} \\
\hline & IP UK (Case) & 18.68 & 21.985 & \\
\hline & IT Malta (Case) & 30.35 & 45.773 & \\
\hline \multirow[t]{3}{*}{ Number of cancelled appointments } & СMHT (Control) & 2.61 & 3.223 & \multirow[t]{3}{*}{0.405} \\
\hline & IP UK (Case) & 3.22 & 3.125 & \\
\hline & IT Malta (Case) & 3.54 & 3.956 & \\
\hline \multirow[t]{3}{*}{ Total Contact time minutes } & СMHT (Control) & 518.59 & 910.235 & \multirow[t]{3}{*}{0.101} \\
\hline & IP UK (Case) & 1090.11 & 1640.860 & \\
\hline & IT Malta (Case) & 1470.63 & 4166.265 & \\
\hline \multirow[t]{3}{*}{ Attendance rate $\%$} & CMHT (Control) & 69.10 & 30.207 & \multirow[t]{3}{*}{0.021} \\
\hline & IP UK (Case) & 54.04 & 29.644 & \\
\hline & IT Malta (Case) & 55.46 & 33.606 & \\
\hline
\end{tabular}

IT Malta had a significantly longer waiting time for the initial assessment when compared to both UK services $(p=0.009)$, Table 2 . The number of missed or cancelled appointments of the HTRYP and the overall attendance rate were similar for both the IT Malta and IP UK services although this was not statistically significant in comparison to CMHT $(p=0.41)$. The total mean contact time per YP were; IT Malta (24.5 hours), IP UK (18.2 hours) and CMHT (8.6 hours).

The HoNOSCA scores at baseline and discharge for both the IT Malta and IP UK services were similar. Both had higher HoNOSCA scores which inferred a greater severity of mental disorder when compared with the CMHT group ( $p<0.001)$, Fig. 1. The CGAS at baseline for IT Malta (mean 46.0, SD \pm 9.4 ) elucidates more impairment when compared to IP UK (mean 51.1, SD \pm 14.0) and CMHT (mean 58.9, SD \pm 5.1). Using Tukey Post-Hoc Test there was a significant difference between baseline CGAS of IT Malta and CMHT ( $p=0.006$, SE 4.1) however there was no significant difference found between the three groups for CGAS on discharge ( $p=0.18)$, Fig. 2. 
The mean number of diagnosis per YP were similar for both the IT Malta and IP UK but differed significantly from the CMHT $X^{2}(36)=95.89, p<0.001$. The most common diagnosis in the CMHT was depression (56.3\%) and anxiety disorder (23.9\%), whereas in IP UK, 52.5\% were diagnosed with substance misuse, $37.5 \%$ had anxiety and depression and $32.5 \%$ had antisocial personality disorder (ASPD), conduct disorder (CD) or oppositional defiant disorder (ODD). The commonest disorder diagnosed in IT Malta was anxiety (30.4\%), followed by attention deficit hyperactivity disorder and attachment disorder (26.1\%) and post-traumatic stress disorder and ASPD/CD/ODD (21.7\%).

Table 3

Medication prescribed by each service $\mathrm{X}^{2}(30)=111.20, \mathrm{p}<0.001$

\begin{tabular}{|llll|}
\hline Treatment & CMHT (Control) & IP UK (Case) & IT Malta (Case) \\
\hline SSRI & $29(40.8 \%)$ & $5(14.3 \%)$ & $6(50.0 \%)$ \\
\hline Methylphenidate & $5(7.0 \%)$ & $1(2.9 \%)$ & $2(16.7 \%)$ \\
\hline Atypical antipsychotics & $1(1.4 \%)$ & $1(2.9 \%)$ & $2(16.7 \%)$ \\
\hline Mood stabilizers & $11(15.5 \%)$ & $2(5.7 \%)$ & $2(16.7 \%)$ \\
Hypnotics & $26(36.6 \%)$ & $3(8.6 \%)$ & $0(0 \%)$ \\
Atomoxetine & $13(18.3 \%)$ & $21(60.0 \%)$ & $0(0 \%)$ \\
\hline
\end{tabular}

The most commonly prescribed medication for IP UK was Atomoxetine $(60.0 \%)$ whereas only $18.3 \%$ YP in $\mathrm{CMHT}$ and $0 \%$ in IT Malta where prescribed this medication. Hypnotics were more commonly prescribed in the CMHT (36.6\%) when compared to both the IP UK (8.6\%) and IT Malta (0\%). The most common medication prescribed in IT Malta were selective serotonin reuptake inhibitors (SSRI) (50\%), Table 4.

Table 4

Therapies offered $X^{2}(30)=111.20, p<0.001$

\begin{tabular}{|llll|}
\hline Therapies & CMHT (Control) & IP UK (Case) & IT Malta (Case) \\
\hline CBT & $8(11.3 \%)$ & $0(0 \%)$ & $2(16.7 \%)$ \\
\hline Supportive psychotherapy & $3(4.2 \%)$ & $4(11.4 \%)$ & $7(58.3 \%)$ \\
\hline Motivational therapy/ DBT, other therapies & $3(4.2 \%)$ & $1(2.9 \%)$ & $7(58.3 \%)$ \\
\hline Home treatment & $10(14.1 \%)$ & $7(20.0 \%)$ & $2(16.7 \%)$ \\
\hline
\end{tabular}

The main modality of therapy for the IT Malta was supportive, motivational and DBT (58\%) whereas home treatment was the main focus for IP UK (20\%) and CMHT (14.1\%) as shown in Table 5.

\section{Conclusions}


Both the IT Malta and IP UK were able to identify, engage and treat a number of YP with multiple complex mental disorders whose needs were not being met by other mental health services. There was no statistical difference between the baseline HoNOSCA and CGAS for both IT Malta and IP UK, indicating that both services were able to identify YP who although not registered within mental health services, were living in the community and suffering from a greater severity of degree of mental disorder than those YP attending the CMHT. Both innovation services had statistically and clinically worse baseline scores than the CMHT. Both IT Malta and IP UK identified YP who were suffering from more than one mental disorder which is greater than is reported in the literature (Jenkins et al., 2009). The HTRYP identified were suffering from complex mental disorders, to the extent that this was affecting their social functioning as evidenced by the demographics, worse HoNOSCA and CGAS scores, higher number of diagnoses and more treatments prescribed.

The lower mean age in Malta could be the result of accepting younger (ages 13 and 14 vs IP UK age 15) YP into the service. It could also be that since IT Malta was based within the CYPS, the HTRYP were identified early from CYPS and referred to IT Malta. The gender difference may be explained as depression was more commonly diagnosed in IP UK and CMHT when compared to Malta and postpuberty depression would be more prevalent in females (Cohen et al., 1993).

IT Malta dedicated triple and IP UK double the amount of time per YP when compared to the CMHT. This study postulates the importance of 'time' being a key factor to successful engagement with a HTRYP and offering a clinically effective treatment. A dedicated outreach team with a high staff to patient ratio working specifically on engaging YP with complex mental disorders and offering them an individualised tailored management plan, was clinically effective.

The significant proportion (frequency $22.1 \%$ ) of HTRYP with neurodevelopmental disorders supports the concept that a developmental approach is relevant and should be used in assessments by psychiatric services into early adult life (Camilleri et al., 2017). A number of HTRYP may have had previously unsatisfactory contact with mental health services (Camilleri et al., 2017). However, through the availability of a more flexible service which facilitated access of referrals into the service, provided a focus on engagement through the use of home and community reviews, the variety of mental health professionals with different training backgrounds, the repeated attempts at contacting the YP via a nurse or psychology assistant rather than receiving cold calls through a letter or clerk and having a MDT with a different set of psychotherapeutic skills increased the possibility of offering a clinically effective intervention to these HTRYP. This intervention helped to reduce their morbidity and mortality through mental disorders (McGorry, Purcell, Hickie, \& Jorm, 2007).

The longer waiting times record by IT Malta could be a result of the stigma associated with the location (CYPS) of this service opposed to being located within a GP surgery like IP UK or, perhaps because IT Malta staff, although were better staffed in terms of numbers than IP UK, were not working within this service full time. Therefore, a recommendation from this study is for such future services to be based outside of mental health facilities and within the community or GP surgeries. 
Generalisability of these findings needs to be done with care since to date no Maltese control group has been identified and compared. However, both IP UK and CMHT groups were matched on a number of demographic factors and severity of mental disorder. Another limitation of this study was the small sample sizes of both the HTRYP services. This was expected considering the nature of the characteristics of the targeted cohort. No formal reliability testing for the data collection process was undertaken, although to minimise any bias a trained clinical researcher carried out the double data checking.

The next steps would be to carry out a qualitative and quantitative follow up study and compare the results of these services and a control CMHT in Malta. This would help elucidate whether the positive clinical change following intervention had a lasting effect on the trajectory of the lives of these YP. Although there was an improvement in the mental state and social function of both IT Malta and IP UK over time, the mental state and social function of these HTRYP remained clinically worse than those of the control group. A recommended study would be to identify moderators and mediators that could help identify which HTRYP suffering from which disorders would benefit from which specific psychotherapeutic interventions.

\section{Declarations}

\section{Ethics approval and consent to participate}

NHS UK ethical approval was gained in June 2013 (ref: 13/NE/ 0150) with amendment approved in April 2014. Caldecott approval together with research and developmental approval in the relevant NHS organisations and Mental Health Services Malta were also gained.

\section{Consent for publication}

Andrea Saliba and Nigel Camilleri give their consent for this study to be published in Child and Adolescent Psychiatry and Mental Health Journal.

\section{Availability of data and materials}

Authors confirm that they have full access to all the data in the study and take responsibility for the integrity of the data in the study and the accuracy of the data analysis.

\section{Competing interests}

The authors have declared that they have no competing or potential conflicts of interest. The Innovations Project was funded by the North East Strategic Health Authority. The study was funded by the Malta Government Scholarship Scheme, and was a National Institute for Health Research (NIHR) Portfolio Study. 


\section{Funding}

The authors are not currently in receipt of any research funding for this study.

\section{Authors' contributions}

Both authors have made substantial contributions to the conception and design of the study and have approved the submitted version. Both authors agree to be personally accountable for their own contributions and for ensuring that questions related to the accuracy or integrity of any part of the work, even ones in which the author was not personally involved, are appropriately investigated, resolved, and documented in the literature.

\section{Acknowledgements}

Statistical advice was sought from Prof Liberato Camilleri at the University of Malta.

\section{References}

1. Camilleri, N., Newbury-Birch, D., McArdle, P., Stocken, D. D., Thick, T., \& Le Couteur, A. (2017). Innovations in Practice: A case control and follow-up study of 'hard to reach' young people who suffered from multiple complex mental disorders. Child and Adolescent Mental Health, 22(1), 49-57. https://doi.org/10.1111/camh.12202

2. Cohen, P., Cohen, J., Kasen, S., Velez, C. N., Hartmark, C., Johnson, J., ... Streuning, E. L. (1993). An Epidemiological Study of Disorders in Late Childhood and Adolescence?I. Age- and Gender-Specific Prevalence. Journal of Child Psychology and Psychiatry, 34(6), 851-867. https://doi.org/10.1111/j.1469-7610.1993.tb01094.x

3. Garralda, M., Yates, P., Psychiatry, I. H.-T. B. J. of, \& 2000, undefined. (n.d.). Child and adolescent mental health service use: HoNOSCA as an outcome measure. Cambridge.Org. Retrieved from https://www.cambridge.org/core/journals/the-british-journal-of-psychiatry/article/child-andadolescent-mental-health-service-use/FDF9A0F25A4887BB4A12D165F874C9A4

4. Gondek, D., Edbrooke-Childs, J., Velikonja, T., Chapman, L., Saunders, F., Hayes, D., \& Wolpert, M. (2017). Facilitators and Barriers to Person-centred Care in Child and Young People Mental Health Services: A Systematic Review. Clinical Psychology and Psychotherapy, 24(4), 870-886. https://doi.org/10.1002/cpp.2052

5. Gowers, S., Harrington, R., ... A. W.-T. B. J. of, \& 1999, undefined. (n.d.). Brief scale for measuring the outcomes of emotional and behavioural disorders in children: Health of the Nation Outcome Scales for Children and Adolescents. Cambridge.Org. Retrieved from https://www.cambridge.org/core/journals/the-british-journal-of-psychiatry/article/brief-scale-for- 
measuring-the-outcomes-of-emotional-and-behavioural-disorders-inchildren/DCB7B874A62003C671BAA3AC7CB4E8A8

6. Green, B., Shirk, S., Hanze, D., ... J. W. the A. A. of C., \& 1994, undefined. (n.d.). The Children's Global Assessment Scale in clinical practice: An empirical evaluation. Elsevier. Retrieved from https://www.sciencedirect.com/science/article/pii/S0890856709641204

7. Green, S. B., \& Salkind, N. J. (2013). Using SPSS for Windows and Macintosh (7th Edition). Pearson. Retrieved from http://www.amazon.com/Using-SPSS-Windows-Macintosh-Edition/dp/0205958605

8. Jenkins, R., Meltzer, H., Bebbington, P., Brugha, T., Farrell, M., McManus, S., \& Singleton, N. (2009). The British Mental Health Survey Programme: Achievements and latest findings. Social Psychiatry and Psychiatric Epidemiology, 44(11), 899-904. https://doi.org/10.1007/s00127-009-0112-7

9. Kroll, L., Woodham, A., Rothwell, J., Bailey, S., Tobias, C., Harrington, R., \& Marshall, M. (1999). Reliability of the Salford Needs Assessment Schedule for Adolescents. Psychological Medicine, 29(4), 891-902. https://doi.org/10.1017/S0033291799008752

10. McGorry, P. D., Purcell, R., Hickie, I. B., \& Jorm, A. F. (2007). Investing in youth mental health is a best buy. Medical Journal of Australia, 187(S7), 5-7. https://doi.org/10.5694/j.13265377.2007.tb01326.x

11. Sheehan, D. V., Sheehan, K. H., Shytle, R. D., Janavs, J., Bannon, Y., Rogers, J. E., ... Wilkinson, B. (2010). Reliability and validity of the mini international neuropsychiatric interview for children and adolescents (MINI-KID). Journal of Clinical Psychiatry, 71(3), 313-326. https://doi.org/10.4088/JCP.09m05305whi

12. Singh, S. P., Paul, M., Ford, T., Kramer, T., Weaver, T., McLaren, S., ... White, S. (2010). Process, outcome and experience of transition from child to adult mental healthcare: Multiperspective study. British Journal of Psychiatry, 197(4), 305-312. https://doi.org/10.1192/bjp.bp.109.075135

13. Stratton, P., Bland, J., Janes, E., \& Lask, J. (2010). Developing an indicator of family function and a practicable outcome measure for systemic family and couple therapy: The SCORE. Journal of Family Therapy, 32(3), 232-258. https://doi.org/10.1111/j.1467-6427.2010.00507.x

\section{Figures}




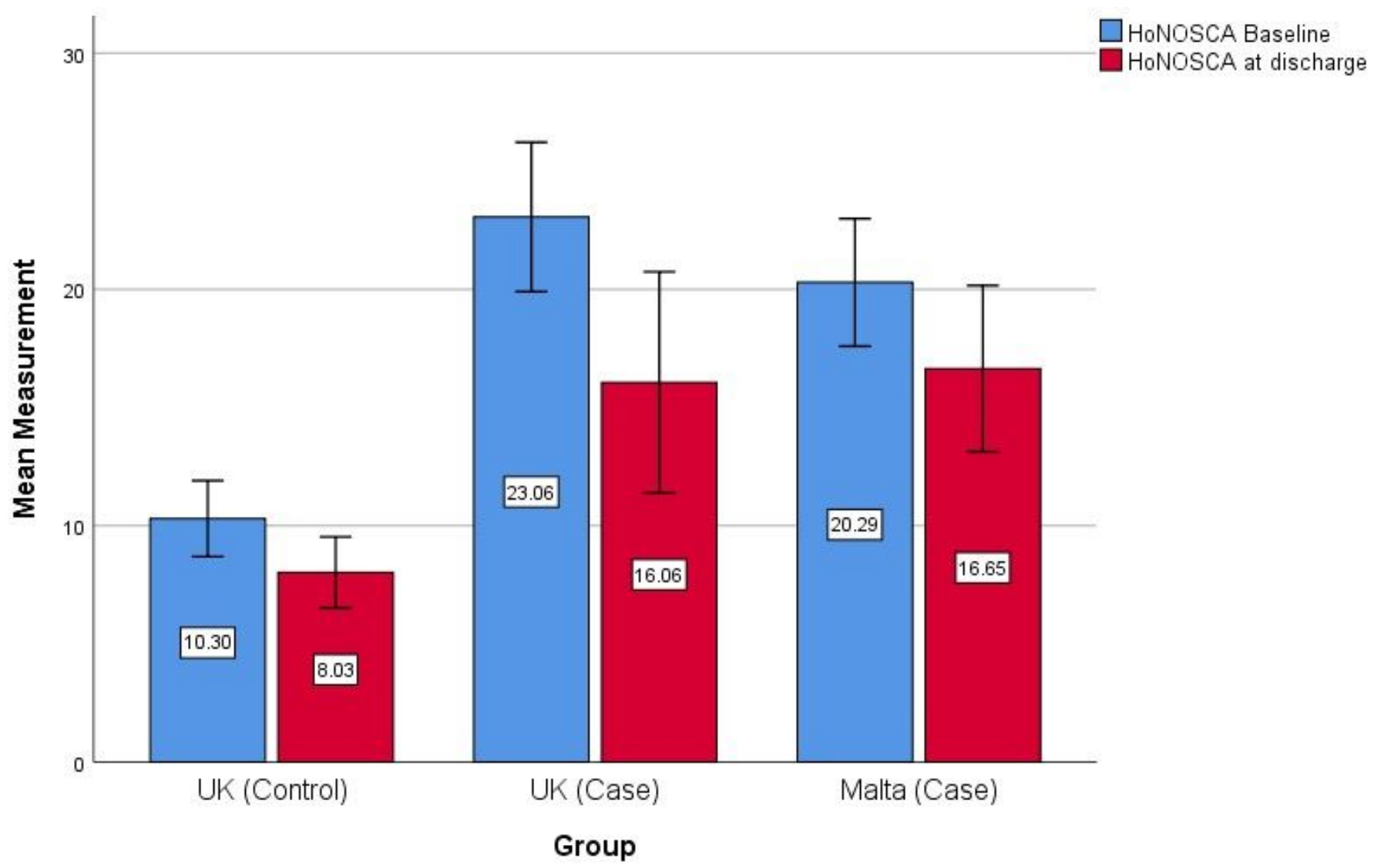

Figure 1

Mean HoNOSCA at baseline and discharge. Baseline 95\% Cl: UK Control [9.89, 12.50], UK Case [16.72, 21.93], Malta Case [18.05, 23.25]. Discharge 95\% Cl: UK Control [6.52, 9.53], UK Case [12.05, 21.01], Malta Case $[13.13,20.16]$. 


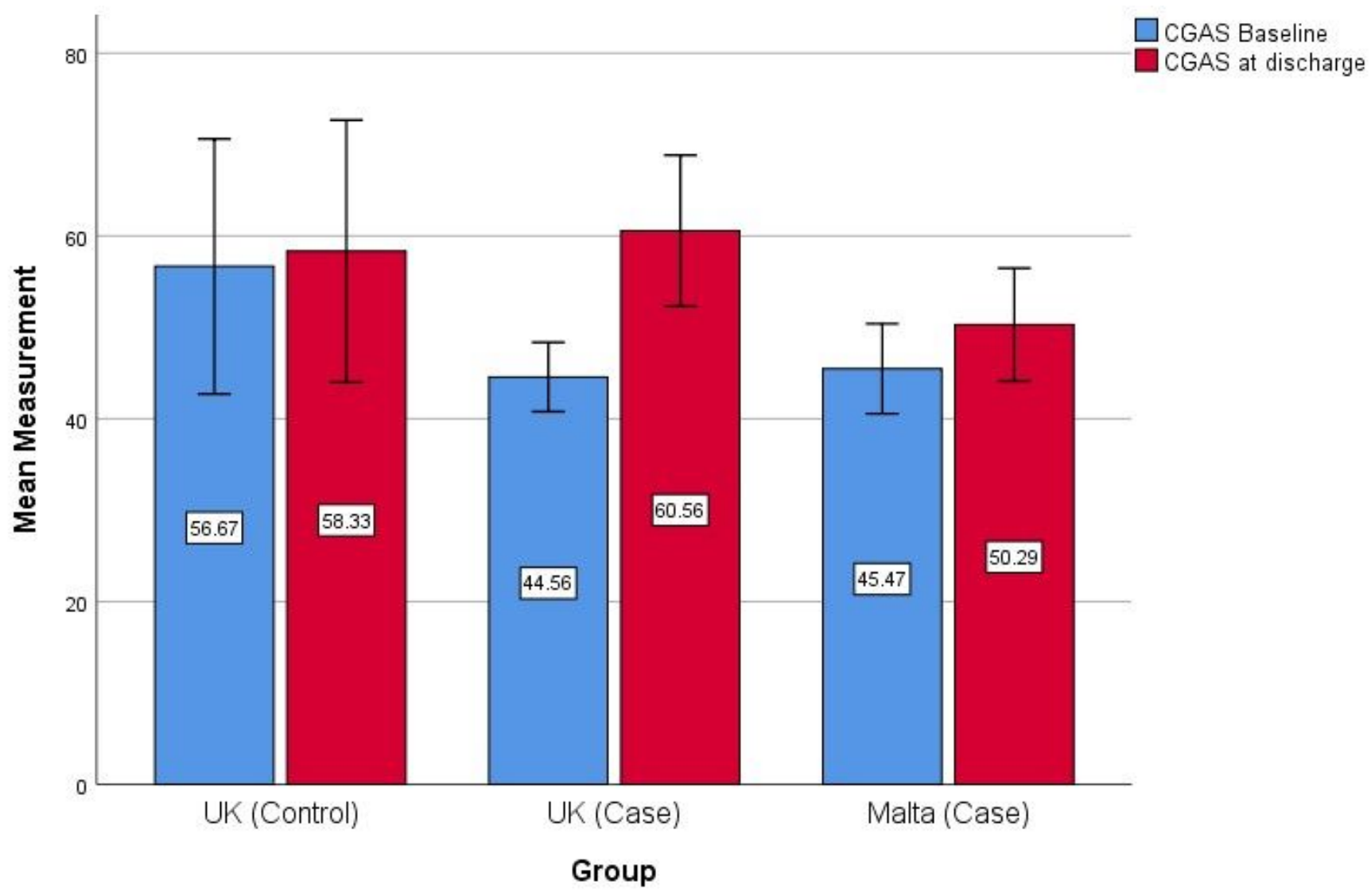

Figure 2

Mean CGAS at baseline and discharge. Baseline 95\% Cl: UK Control [52.95, 64.83], UK Case [46.56, 55.64], Malta Case [41.53, 50.37]. Discharge 95\% Cl: UK Control [46.26, 69.45], UK Case [50.70, 67.42], Malta Case $[44.13,56.46]$. 